\title{
Fisioterapia na Colômbia
}

Mais do que nunca, é preciso um tempo para repensar, descrever e refletir sobre as histórias da fisioterapia na Colômbia.

Embora os primeiros estudos sobre essa história tenham identificado a existência de pelo menos três períodos - vale recordar: práticas dispersas, processo de institucionalização e consolidação profissional, relocalização profissional e desenvolvimento disciplinar -, hoje é necessário mostrar que essa visão linear e ocidental da história é apenas uma análise segundo intervalos que torna invisíveis outras histórias, outras práticas, outras perspectivas da profissão. Vamos nos referir a um panorama geral, entendendo que essa visão é tendenciosa e parcial em um país multicultural, diverso e historicamente desigual.

A formação institucional se inicia em 1952, como carreira técnica, feminina, para moças da elite urbana, com dois anos de formação e com vistas à formação de mão de obra para atender ao segundo momento da epidemia de poliomielite e ao grande número de acidentes de um país que iniciava seus esforços para se industrializar - elementos todos cuja importância ainda não conseguimos medir, deixando questões de gênero, identidade profissional, subordinação médica e dificuldades tarifárias numa invisibilidade pouco estudada. Nesse primeiro momento, a formação é instrumental, focada em técnicas e estratégias de abordagem.

No mesmo período, em 1953, a Associação Colombiana de Fisioterapia ${ }^{1}$ (ASCOFI) começa seus trabalhos como entidade gremial a fim de promover e divulgar a nova profissão no país. Em 1954, através do Decreto no 1.056 , o exercício da profissão é regulamentado. Mas o fato de a adesão à entidade não ser obrigatória e da manutenção do ASCOFI exigir taxas anuais de manutenção acabam colocando em risco sua sobrevivência.

A partir de meados dos anos 1960, a formação é elevada ao nível da graduação, com aumento do tempo de curso para três anos, mas não como resultado de uma análise do desenvolvimento alcançado nestes primeiros momentos, e sim por pressões isoladas de instituições universitárias que não conseguem encaixar a formação em fisioterapia em seus currículos. Nessa época havia cinco programas, três públicos e dois privados, localizados nas capitais dos municípios. Dentre esses, apenas dois estavam na capital do país. Em 1976, através da Lei no 9, o caráter universitário da formação é determinado, o que foi mantido.

Nesse sentido, a Lei no 30, de 1992, é um claro exemplo dessa tarefa. Naquele período, o ministério, sob a visão neoliberal do livre mercado, legitima a abertura de mais cursos de fisioterapia, que hoje chegam a 35 , cinco deles públicos. Em geral, tais cursos duram cinco anos, com possível articulação dos últimos períodos de formação com matérias de pós-graduação, aprofundando os conhecimentos adquiridos e facilitando a transição para o próximo nível de formação, dada a existência de múltiplos programas de mestrado na área, alguns inclusive interdisciplinares. Foi adotado o sistema acadêmico de crédito como medida do tempo de formação.

Em 21 de agosto de 1998, com o nome de Associação Colombiana de Faculdades de Fisioterapia (ASCOFAFI), os programas de formação se reúnem com o objetivo de fazer convergir seus interesses. Seus processos conseguiram, por exemplo, unificar sob a denominação "fisioterapeuta" os títulos da área oferecidos em todo o território nacional.

Em 1999, através da Lei no 528, a fisioterapia consolidou-se como "profissão liberal, na área da saúde, com formação universitária ...”2. Esta lei, pioneira na regulação de profissões na Colômbia, reúne sob seu perfil de atuação o mesmo objeto de estudo que propõe: o movimento corporal humano. Na Colômbia, a formação específica em quiropraxia e osteopatia não é permitida, uma vez que essas práticas são consideradas como aprofundamentos da atuação do fisioterapeuta.

Em 2010, o governo dita uma nova regulamentação para o exercício da função pública das profissões da área da saúde, o Decreto $n^{\circ} 4.192^{2}$, que concede a gestão de determinadas funções - incluindo a regulamentação do registro único de profissionais de saúde e a emissão do 
cartão profissional, com alcance nacional - à única instância reconhecida desde então como lugar de diálogo sobre o desenvolvimento dessas questões: os conselhos de classe profissional. Assim, em 27 de julho de 2015, o Colégio Colombiano de Fisioterapia (COLFI) assume funções públicas.

Chegamos então a 2019, e há colegas sendo assassinados no exercício da profissão em domicílio, colegas com medidas de proteção para suas vidas e de seus familiares por terem protestado, pressionados por um modelo médico e patriarcal que quer retornar ao tempo das "ordens médicas de tratamento". O trabalho combinado entre ASCOFI-ASCOFAFI-COLFI, e pela primeira vez com a participação da Associação Colombiana de Estudantes de Fisioterapia (ACEFIT), com um plano de desenvolvimento profissional unificado, tornou-se a proposta esperançosa de resistência.

Tudo isso enquanto a Colômbia enfrenta os desafios da assinatura de um acordo de paz entre várias forças saídas de um conflito. Com isso, justifica-se um tempo de reconfiguração social contínua, que credencia a fisioterapia para essas novas condições históricas, territoriais e sociopolíticas.

\author{
Aydee Luisa Robayo \\ Professora associada \\ Universidad Nacional de Colombia \\ Vice-presidenta COLFI \\ Calle 45\#17-52 Ap. 4012 - Bogotá - Colômbia
}

\section{REFERÊNCIAS}

1. Paez, SV. Historia de la fisioterapia en Colombia [Internet]. Prezi. San Francisco; 2014 [cited 2019 July 22]. Available from: https://prezi.com/4ev061leqqng/ historia-de-la-fisioterapia-en-colombia/.

2. Minsalud. Boletín de Prensa no. 072 de 2011 [Internet]. Bogotá: Minsalud; 2011 [cited 2019 July 22]. Available from: https://www.minsalud.gov.co/paginas/minprotecci\%C3\%B3ndelegar\%C3\%A1funcionesp\%C3\%BAblicasacolegiosprofesionalesdel\%C3\%A1readelasalud. aspx. 